\title{
Smell and taste function in the visually impaired
}

\author{
RICHARD S. SMITH and RICHARD L. DOTY \\ University of Pennsylvania, Philadelphia, Pennsylvania \\ GARY K. BURLINGAME \\ Philadelphia Water Department, Philadelphia, Pennsylvania \\ and \\ DONALD A. MCKEOWN \\ University of Pennsylvania, Philadelphia, Pennsylvania
}

\begin{abstract}
Surprisingly few quantitative studies have addressed the question of whether visually impaired individuals evidence, perhaps in compensation for their loss of vision, increased acuteness in their other senses. In this experiment we sought to determine whether blind subjects outperform sighted subjects on a number of basic tests of chemosensory function. Over 50 blind and 75 sighted subjects were administered the following olfactory and gustatory tests: the University of Pennsylvania Smell Identification Test (UPSIT); a 16-item odor discrimination test; and a suprathreshold taste test in which measures of taste-quality identification and ratings of the perceived intensity and pleasantness of sucrose, citric acid, sodium chloride, and caffeine were obtained. In addition, 39 blind subjects and 77 sighted subjects were administered a single staircase phenyl ethyl alcohol (PEA) odor detection threshold test. Twenty-three of the sighted subjects were employed by the Philadelphia Water Department and trained to serve on its water quality evaluation panel. The primary findings of the study were that (a) the blind subjects did not outperform sighted subjects on any test of chemosensory function and (b) the trained subjects significantly outperformed the other two groups on the odor detection, odor discrimination, and taste identification tests, and nearly outperformed the blind subjects on the UPSIT. The citric acid concentrations received larger pleasantness ratings from the trained panel members than from the blind subjects, whose ratings did not differ significantly from those of the untrained sighted subjects. Overall, the data imply that blindness, per se, has little influence on chemosensory function and add further support to the notion that specialized training enhances performance on a number of chemosensory tasks.
\end{abstract}

The question of whether blind persons evidence increased acuteness in their other senses has been a subject of controversy for over a century. In 1883 Sir Francis Galton wrote, "Blind persons are reputed to have acquired in compensation for the loss of their eyesight an increased acuteness in their other senses" (p. 21). However, his own studies suggested that such compensation did not occur. For example, in relation to his studies of touch, he concluded, "the blind lads who showed the most delicacy of touch and won the little prizes I offered to excite emulation, barely reached the mediocrity of the various

This work was supported by Grant DC 00161 from the National Institute on Deafness and Other Communication Disorders. We thank Richard Frye, Amanda Jones, Rachel Kurian, John Pierce, and R. Gregg Settle for their assistance. We are particularly grateful to Veronica McGuigan of the Associated Services for the Blind, Philadelphia, Pennsylvania; Dennis Garza of the Virginia Rehabilitation Center for the Blind, Richmond, Virginia; and Glenn DiChiera of the Maryland School for the Blind, Baltimore, Maryland; all provided invaluable advice and assistance, including coordination of subject recruitment. Correspondence should be addressed to R. L. Doty, Smell and Taste Center, 5 Ravdin Pavilion, Hospital of the University of Pennsylvania, 3400 Spruce Street, Philadelphia, PA 19104. sighted lads of the same age whom I had previously tested"' (p. 21).

Surprisingly few studies have addressed this issue in regard to the chemical senses, although anecdotal reports abound. For example, William James (1890) mentioned a blind woman employed in a mental institution who was said to be capable of sorting the linen of inmates by odor after it came from the wash. James Mitchell, a congenitally deaf and blind boy, was allegedly able to follow the odor trail of a person for several miles (Stewart, 1815), and a blind girl tested by Gault (1923) reportedly could distinguish by smell, in 50 of 54 cases, between variouscolored yarns of different textile fabrics. Bilancioni (1927) described hyperosmia in a woman who was blind since birth. More recently, Helen Keller claimed to recognize most of her friends and visitors by their odors (Hicks, 1965). Since individual recognition on the basis of body odor has been demonstrated in persons with normal sight (e.g., Porter \& Moore, 1981; Wallace, 1977), the degree to which the latter feat is dependent upon the loss of sight is unclear.

Six major studies have appeared in the last 125 years that have sought to provide empirical data on this ques- 
tion. The first of these studies was that by Griesbach (1889), who evaluated, using the Zwaardemaker drawtube olfactometer, the olfactory sensitivity of 20 blind subjects and 40 sighted controls. Individuals with abnormal nasal function and persons believed to have tobacco-related olfactory deficits were excluded from the study. This wellcontrolled and comprehensive early study found no differences in olfactory function between blind and sighted subjects.

An opposite conclusion was reached twenty years later in a study by Mahner (1909). In this work, 4 blind, 4 deafmute, and 4 normal children between 8 and 14 years of age were tested for their ability to discriminate between two different-sized puffs of two stimuli-Lily of the Valley perfume and a sulfur-smelling agent. Mahner concluded that the blind subjects were superior to the other two groups in making this discrimination. Interestingly, the deaf-mutes were also found to be superior to the controls. Evaluation of taste responsivity to two differentsized puffs of each of three stimuli (chloroform, ether, and a $40 \%$ solution of acetic acid) suggested greater sensitivity in the blind subjects. Unfortunately, however, the results of this study are suspect, since (a) stimulus volume rather than stimulus concentration was the independent variable (potentially providing tactile cues related to pressure, volume, and duration of stimulation); (b) the number of subjects tested was small; and (c) several of the stimuli (i.e., sulfur, ether, and chloroform) were likely able to stimulate the trigeminal, as well as the olfactory or gustatory, system.

Despite these limitations, Mahner's observation of greater olfactory sensitivity in blind individuals received support from a subsequent study of 20 blind subjects published by Bertoloni in 1942. Bertoloni, who used the Elsberg blast-injection procedure (Elsberg \& Levy, 1935), noted enhanced olfactory function in individuals whose blindness either was congenital or had been present for at least six years. Several subjects who had apparent olfactory deficits were eliminated from the study group. As in the case of Mahner's study, Bertoloni's sensitivity measure was confounded by stimulus pressure and volume artifacts (see Jerome, 1942; Jones, 1953; Wenzel, 1948).

In contrast to the findings of Mahner and Bertoloni, and in accord with the findings of Griesbach (1889), Cherubino and Salis (1957) found no evidence of enhanced olfactory sensitivity in blind persons. Thirty-one blind subjects between the ages of 5 and 35 years, 55 deaf-mute subjects between the ages of 10 and 15 years (apart from 1 aged 19 years), and 86 normal subjects of similar ages were tested. Importantly, each nasal cavity was tested separately with each of eight stimuli (lavender, coffee, citral, rhodinol, vanillin, pyridine, rose water, and peppermint) using the method of Fortunato and Niccolini. This method, although based upon an injection procedure, overcomes the inherent problems of the Elsberg blast-injection technique since (a) normal sniffing is allowed, and (b) the odor is injected into an inhaled airstream made up of a relatively large volume of air (thereby eliminating or minimiz- ing the subject's perception of volume and pressure changes during a stimulus trial).

No difference between blind and sighted subjects was found by Boccuzzi (1962) in a comparatively thorough and well-controlled study. This research used Fortunato and Niccolini's method to assess sensitivity to coffee, vanillin, and citral in 101 blind subjects (including 31 congenitally blind and 65 who had been blind for at least 7 years) and 100 sighted controls. Despite the fact that no overall differences were observed between the sighted and blind subjects, when only data from persons with aboveaverage acuity (i.e., individuals requiring an injection of $5 \mathrm{ml}$ or less to produce a noticeable olfactory sensation) were evaluated, the blind reportedly outperformed the sighted. No differences were observed between the test scores of subjects whose blindness was acquired and those whose blindness was congenital.

The most recent study addressing this issue was performed by Murphy and Cain (1985). These authors examined the ability of 20 sighted and 20 blind adults, ranging in age from 19 to 66 years, to identify 80 odors familiar to most people and to detect, in a single ascending series threshold task, the odor of n-butyl alcohol. This researchthe first to examine odor-identification ability-reported the somewhat paradoxical finding that the blind subjects had lower sensitivity than the sighted subjects, yet performed better on the test of odor identification. These authors also noted that both the sighted and the blind subjects performed better on a second test occasion, implying that practice improves the performance of subjects on both detection and identification tasks, in accord with observations of others (Doty, Snyder, Huggins, \& Lowry 1981; Engen, 1960; Wysocki, Dorries, \& Beauchamp, 1989).

It is apparent from the aforementioned studies that there is lack of consensus as to the effect of blindness on the sense of smell and that the breadth of tests used to examine chemosensory function has been rather limited. Most studies have used only tests of odor threshold and several of these tests are suspect on methodological grounds. With the exception of the study by Mahner (1909), the gustatory function of the blind has not been formally evaluated. Therefore, the purpose of the present study was to examine, using a battery of well-validated olfactory and gustatory tests, the chemosensory function of a relatively large number of blind individuals and to compare their test scores with those found in sighted individuals, including trained members of the Philadelphia Water Department's water quality evaluation panel.

\section{METHOD}

\section{Subjects}

The overall study group consisted of 56 legally blind and 91 sighted persons; as indicated in the results section, most, but not all, were administered all of the tests described below. ${ }^{1}$ The olfactory data of 7 subjects who evidenced scores less than 34 on the University of Pennsylvania Smell Identification Test (UPSIT) were excluded from evaluation. ${ }^{2}$ 
Of the blind subjects, who were volunteers from the Associated Services for the Blind in Philadelphia, PA, the Virginia Rehabilitation Center for the Blind in Richmond, VA, and the Maryland School for the Blind in Baltimore, MD, 31 had congenital impairment, 18 had noncongenital impairment of more than 10 years' duration, and the remainder had had noncongenital impairment for less than 10 years. Twenty-three of the blind subjects were male and 33 were female, with a mean age of 41.85 years [standard deviation $(S D)=12.69]$ and an average of 13.16 years of education $(S D=2.54)$. Current smokers comprised $14.3 \%$ of the blind group, while $32.1 \%$ were previous smokers and $53.6 \%$ had never smoked.

Of the sighted adults, 23 were employees of the Philadelphia Water Department who had served as members of a water quality evaluation panel and had completed a training program designed to optimize their performance on this panel. Seventeen were male and 6 were female, with a mean age of $40.57(S D=10.80)$ and, on average, 16.13 years of education $(S D=1.77)$. Current smokers made up $8.7 \%$ of this group, while $47.8 \%$ had smoked in the past and $43.5 \%$ had never smoked.

The remaining 68 sighted subjects were untrained, and were recruited from the Philadelphia community, largely on the basis of fliers and advertisements requesting subjects. Twenty-six were male and 42 were female, with a mean age of $38.57(S D=10.78)$ and an average of 15.29 years of education $(S D=2.05)$. Of this untrained sighted group, $11.8 \%$ were smokers, $36.8 \%$ had previously smoked, and $51.5 \%$ had never smoked.

With the exception of the Philadelphia Water Department employees (who received their regular remuneration during the testing period), the subjects were paid $\$ 20$ each for their participation.

\section{Philadelphia Water Department Panel Training Procedures}

Other than that they did not exhibit anosmia or marked hyposmia at the time of initial participation (i.e., that they evidenced UPSIT scores greater than 33), no specific criteria had been used to select the panel members. All had served on the panel for over a year (some for several years) and had received extensive and continued training once or twice a week (with the exception of vacation periods) in formal panel sessions. The general training procedures are discussed in detail elsewhere (Bartels, Burlingame, \& Suffet, 1986; Mallevialle \& Suffet, 1987). The organoleptic procedures used at the Philadelphia Water Department are derived from those used in Flavor Profile Analysis (FPA), a method developed for the food industry (e.g., Baker, 1962; Cairncross \& Sjostrom, 1950). Essentially, the panelists are provided, in training sessions, with reference standards of substances found on occasion in municipal drinking water and are taught to recognize them, either as smells or as tastes, in the panel setting. Such substances are: benzaldehyde, chlorine, cloves, cod liver oil, coumarin, cumene, dimethyl sulfide, diphenyl ether, dodecanol, dried grass, eucalyptol, geosmin, heptanal, 2-heptanone, hexanal, hexanol, d-limonene, 2methyl-iso-borneol, methyl methacrylate, rubber hose, soap, styrene, wood shavings, and xylene. Similar exercises are given for sucrose, sodium chloride, citric acid, and quinine hydrochloride dihydrate. During the panel sessions, feedback and group consensus are obtained when off odors or tastes are detected, in accordance with standard panel procedures (see Caul, 1957).

\section{Test Procedures}

The chemosensory tests that were administered in the current study were as follows:

The University of Pennsylvania Smell Identification Test (UPSIT). This standardized test (commercially available as the Smell Identification Test, ${ }^{\text {'m }}$ Sensonics, Inc., Haddon Heights, NJ) is described in detail elsewhere (Doty, Frye, \& Agrawal, 1989; Doty, Shaman, \& Dann 1984). Briefly, a subject is required to identify, in a fouralternative multiple-choice format, each of 40 odorants presented on microencapsulated "scratch and sniff"' labels. One of the test items, for example, reads, "This odor smells most like: (a) chocolate; (b) banana; (c) onion; or (d) fruit punch." The test is forced choice (i.e., the subject is required to provide a response even if no smell is perceived). The number of items out of 40 that is answered correctly serves as the dependent measure.

Bilateral phenyl ethyl alcohol odor detection threshold test. This test incorporates the rose-smelling odorant phenyl ethyl alcohol (PEA) diluted in USP-grade light mineral oil. The concentration series ranges from -10.00 to $-2.00 \log _{10}$ in half-log steps ( $(\mathrm{vol} / \mathrm{vol})$. A trial consists of the presentation of two 100-ml sniff bottles (one containing a given PEA concentration and the other diluent alone) in rapid succession and in random order (see Deems \& Doty, 1987; Doty et al., 1978; Doty, Gregor, \& Settle, 1986). The subject is required to report which of the two bottles contains the strongest smell. If no difference is perceived, a guess is required (i.e., the test is forced choice). The initial trial is presented at the -6.50 $\log \mathrm{vol} / \mathrm{vol}$ concentration. If a correct response occurs on this trial, additional trials are presented at that concentration until either (a) a miss occurs or (b) five consecutive correct responses occur. In the case of a miss, the procedure is repeated at 1 log concentration step higher (i.e., at the $-5.50 \log$ concentration). If an incorrect response again occurs before five consecutive correct trials are made at that concentration, the procedure is again repeated at $1 \log$ concentration step higher $(-4.50 \log$ concentration), and so on. When five consecutive correct trials occur at a given concentration, the next trial is presented at a half-log concentration step lower and, from this point on, (a) only one or two trials are presented at a given concentration before movement to another concentration occurs (movement is up when the first or the second trial is missed and down when neither trial is missed), and (b) all such movements are made in half-log concentration steps. This procedure is continued until seven reversals of the "staircase" occur. The geometric mean of the last four staircase-reversal points is used as the threshold measure.

Odor discrimination test. In this test, the subject is presented with 16 sets of three microencapsulated odorants (two are the same and one is different) on separate pages of a test booklet. The subject is asked to select the "odd" or "different" odor within each triad. The odorants are preselected to be equivalent in perceived intensity, and are presented in a predetermined order. This test provides a basic determination of whether an individual can discriminate qualitative differences among odorants independent of his or her ability to recognize their name or recall odor percepts from longerterm memory. This test is a variant of the triangle match-to-sample test described by Eichenbaum, Morton, Potter, and Corkin (1983). The number of correctly answered items serves as the test score.

Suprathreshold whole-mouth taste identification, intensity, and pleasantness test. In this test, five concentrations of sucrose $(0.08$, $0.16,0.32,0.64$, and $1.28 \mathrm{M})$, citric acid $(0.0026,0.0051,0.0102$, 0.0205 , and $0.0410 \mathrm{M})$, sodium chloride $(0.032,0.064,0.128$, 0.256 , and $0.512 \mathrm{M})$, and caffeine $(0.0026,0.0051,0.0102,0.0205$, and $0.0410 \mathrm{M}$ ) are tasted by a subject in counterbalanced order, with distilled/deionized water rinsings interspersed between presentations (Amsterdam, Settle, Doty, Abelman, \& Winokur, 1987). Each $10-\mathrm{ml}$ stimulus is presented twice, resulting in a total of $\mathbf{4 0}$ trials per subject. The subject is required (a) to indicate whether a sweet, sour, bitter, or salty taste was perceived, and (b) to rate the perceived intensity and pleasantness of each solution on fullyanchored nine-point category scales (for intensity, $1=$ no taste and 9 = extremely strong taste; for pleasantness, $1=$ dislike extremely and $9=$ like extremely). The percentage of stimuli correctly identified, as well as the mean category ratings, serve as the dependent measures.

\section{Statistical Analyses}

For the UPSIT, odor threshold, odor discrimination, and taste identification test data, an analysis of covariance (ANCOVA; covariates $=$ age, years of education) was initially applied to each data 
set using test group (blind, untrained sighted, trained sighted), gender, smoking group (never, previous, current), and their interactions as independent variables. Because neither the education covariate nor any of the interactions were statistically significant in any analysis, these variables were dropped from subsequent analyses to increase power. The final analyses for these tests were test group $\times$ gender $\times$ smoking group ANCOVAs with age as a covariate. Post-hoc tests were performed using the Tukey $H S D$ test with the Tukey-Kramer adjustment for unequal sample sizes (Wilkinson, 1990).
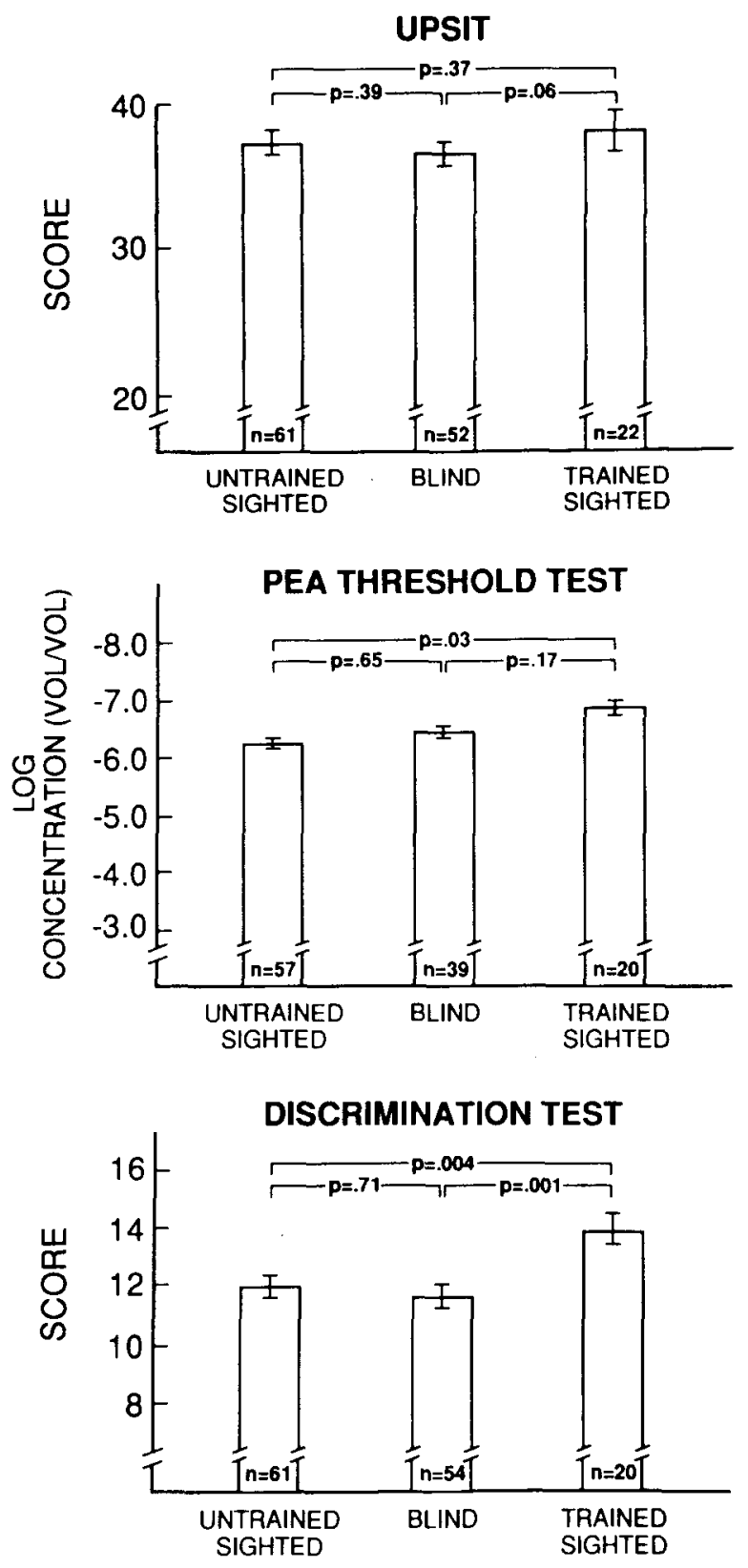

Figure 1. Mean ( \pm SEM) scores for the University of Pennsylvania Smell Identification Test (UPSIT), the phenyl ethyl alcohol (PEA) detection threshold test, and the 16-item odor discrimination test for each study group; $p$ values reflect Tukey $H S D$ post-hoc tests with the Tukey-Kramer adjustment for unequal sample sizes (Wilkinson, 1990).

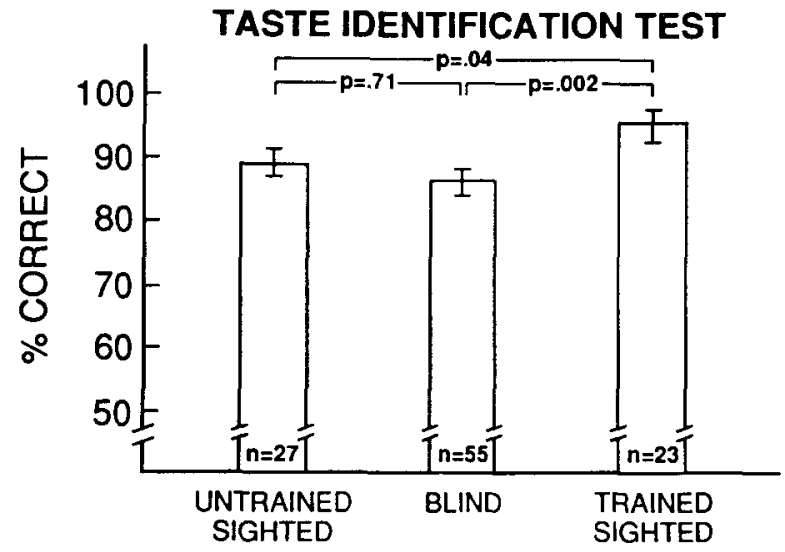

Figure 2. Mean ( $\pm S E M$ ) taste quality identification test scores for each study group; $p$ values reflect Tukey HSD post-hoc tests with the Tukey-Kramer adjustment for unequal sample sizes (Wilkinson, 1990).

For the taste intensity and pleasantness ratings, similar analyses were performed, except that tastant concentration served as a repeated measures independent variable. To assess whether potential relationships existed between some variables (e.g., between duration of blindness and magnitude of sensory test scores), Pearson correlation coefficients were computed.

\section{RESULTS}

\section{Olfaction}

As can be seen in Figure 1, the blind subjects, on average, did not significantly outperform their untrained sighted counterparts on any of the olfactory tests. However, the trained sighted subjects outperformed the untrained sighted and blind subjects on the odor discrimination test as well as the untrained sighted subjects on the PEA detection threshold test, and nearly outperformed the blind subjects on the UPSIT $(p=.06)$. Age proved to be a significant covariate for the UPSIT and odor discrimination tests, but not for the PEA threshold test $(p s<$ $.01)$. The $F$ and $p$ values for the subject-group factor in the ANCOVAs were as follows: UPSIT $[F(2,128)=$ $2.96, p=.07]$; detection threshold $[F(2,129)=4.26$, $p=.02]$; odor discrimination $[F(2,128)=7.17, p=$ .001]. The significance values of the Tukey $H S D$ posthoc comparisons are shown in Figure 1.

\section{Gustation}

The trained sighted subjects scored higher than both the untrained sighted subjects and the blind subjects on the taste identification test; the average scores of the latter two groups did not differ significantly from one another [see Figure 2; subject group $F(2,98)=5.46, p=$ $.006]$. No significant differences were found between the groups in the magnitude or form of the suprathreshold taste intensity rating functions (Figure 3). However, in the case of the taste pleasantness ratings for citric acid (Figure 4), a significant main effect of group appeared in the ANCOVA $[F(2,98)=3.34, p=.04]$. This was 


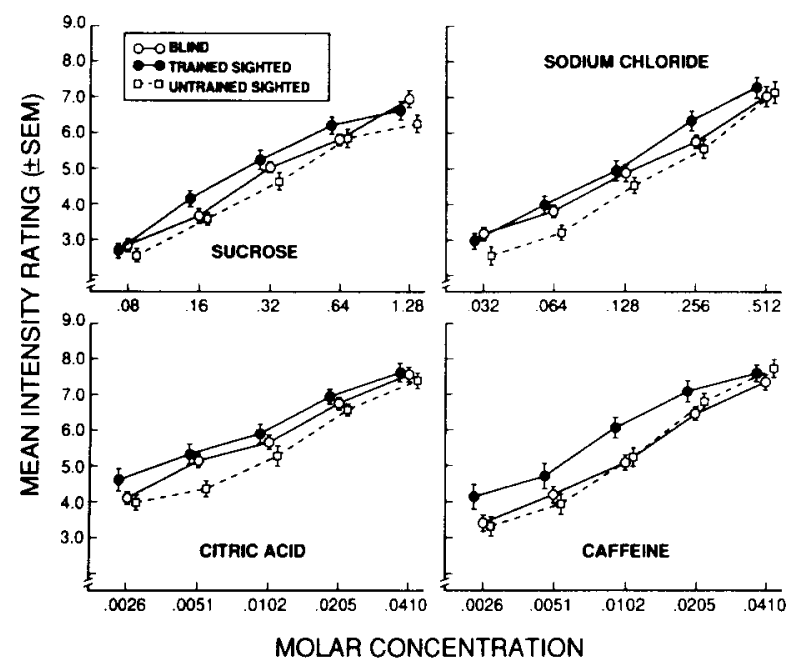

Figure 3. Mean ( \pm SEM) intensity ratings as a function of tastant concentration for each study group.

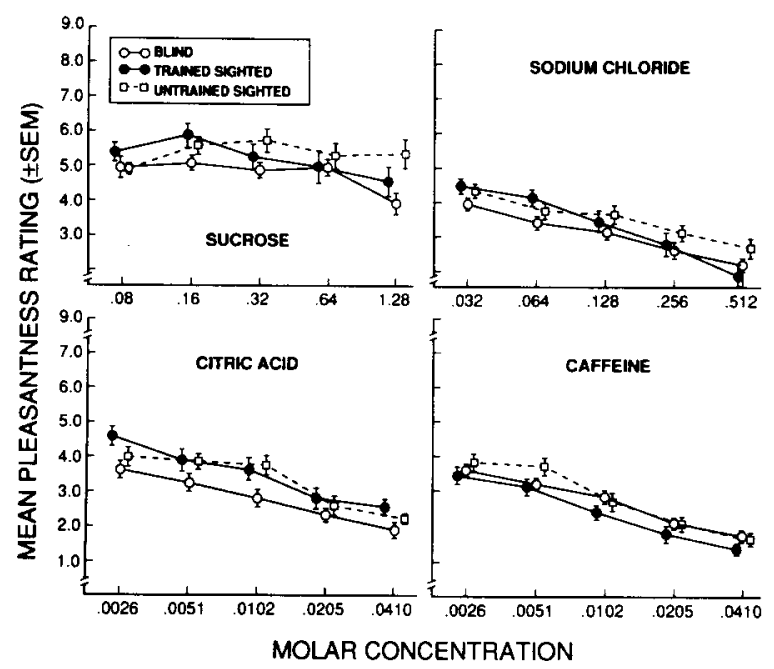

Figure 4. Mean ( $\pm S E M$ ) pleasantness ratings as a function of tastant concentration for each study group.

a reflection of the fact that the pleasantness ratings of the trained subjects were higher than those of the blind subjects, whose ratings did not differ significantly from those of the untrained sighted subjects [Tukey $F(1,98)=5.48$, $p=.02]$.

\section{Relationship Between Test Scores and Degree or Duration of Blindness}

Within the blind group, no association was found between the magnitude of any olfactory or gustatory measure and the duration of blindness (Pearson $r s$, all $p s>$ .20). Furthermore, ANCOVAs revealed no statistically significant differences for any test measure between the test scores of individuals whose blindness was congenital and those for whom it was acquired.

\section{DISCUSSION}

The present study supports earlier observations of Boccuzzi (1962), Cherubino and Salis (1957), and Griesbach (1889) that blindness exerts no major influence on the ability to smell, and is in contrast to the studies of Bertoloni (1942), Mahner (1909), and Murphy and Cain (1985). This work also demonstrates that the suprathreshold gustatory function of blind individuals is, for all practical purposes, equivalent to that of untrained sighted individuals, and confirms Boccuzzi's (1962) observation that there are no differences between the olfactory function of congenitally blind individuals and that of individuals with acquired blindness.

The superior performance by the members of the Philadelphia Water Department's quality evaluation panel on a number of the tests administered in this study likely reflects their training in the detection and discrimination of odorants and tastants, since (a) they were of the same general age and educational background as the members of the other subject groups and (b) practice, training, or mere exposure to chemosensory stimuli is known to improve performance on odor and taste detection and identification tasks (e.g., Doty et al., 1981; Engen, 1960; McAuliffe \& Meiselman, 1974; Murphy \& Cain, 1985; Rabin \& Cain, 1986; Wysocki et al., 1989). The fact that the Water Department group, in contrast to the other two groups, was comprised of more men than women cannot explain its better performance since, when sex differences are present in chemosensory studies, women typically outperform men (Doty, 1978, 1986).

This experiment suggests that the absence of superior performance on the part of blind subjects, as well as its presence among trained sighted subjects, occurs for a number of chemosensory tasks. Whether this reflects commonality among such tasks is not known, although indirect support for such a notion comes, at least for the sense of smell, from a recent principal components analysis of 10 olfactory tests (including tests of detection threshold, odor identification, and odor discrimination). This study found that most of the tests were intercorrelated and loaded on a common component (Doty, Smith, McKeown, \& Raj, 1993). Interestingly, the suprathreshold odor intensity and pleasantness rating measures loaded on components separate from this common one, implying that they measure elements of variance somewhat distinct from those measured by the other tests. If a similar phenomenon holds for taste, then the absence of superior performance in the present study on the part of the trained sighted subjects on the suprathreshold taste intensity rating tasks and three of the four hedonic rating tasks could reflect the specific nature of these tests (e.g., the tasks may simply be less sensitive to training effects). On the other hand, the lack of enhanced performance on these tasks could be a reflection of less experience on the part of the panel members in rating the relative intensity and pleasantness of the stimuli in question.

The basis for the discrepant findings among previous studies on this topic is not known, although it is of in- 
terest that those studies that reported no differences between blind and sighted subjects incorporated larger subject samples than those that found differences $(n s=60$, 117 , and 201 vs. 12,20 , and 40 , respectively). Although the findings of Bertoloni (1942) and Mahner (1909) can be discounted on methodological grounds, the observation by Murphy and Cain (1985) that blind subjects identify odors better than sighted ones, yet have diminished threshold sensitivity, cannot be similarly dismissed. It should be noted, however, that the odor identification task in Murphy and Cain's study was quite different from the one employed in the current study, in that 80 stimuli were presented and the subjects were required to identify them without having forced-choice response alternatives available. If blind individuals are better than sighted ones at recalling the names of odors from memory, better relative performance by the blind on such a task would be expected. A forced-choice test, such as the UPSIT, presumably cues retrieval processes more readily and therefore may not be sensitive to this difference. In the case of the detection threshold measure, the present study used a single staircase procedure that incorporated the odorant phenyl ethyl alcohol, whereas the Murphy and Cain study used a single ascending trial that incorporated butanol. Whether the difference in threshold sensitivity noted between their study and the present one reflects differences in the stimulus evaluated, the psychophysical procedure, or other factors requires additional study.

Why the trained sighted subjects rated the taste of citric acid as less unpleasant than did the blind subjects is not known either. It is conceivable that, as a result of their panel experience, they had more exposure to the taste of citric acid and that such exposure mitigated, to some degree, their tendency to perceive its taste as unpleasant. Precedence for this concept comes from studies which indicate that prior exposure to initially unpleasant taste or smell stimuli decreases the degree to which they are perceived as unpleasant (see Cain \& Johnson, 1978; Pliner, 1982; Rogers \& Hill, 1989). An extreme example of the influences of prior experience with a tastant on subsequent preferences comes from a study reporting that Indian laborers, who ingest large quantities of sour foods, rate sour-tasting stimuli as pleasant, with the degree of pleasantness increasing with stimulus concentration (Moskowitz, Kumraiah, Sharma, Jacobs, \& Sharma, 1975). This was in contrast to the responses of Indian medical students and Westerners, which were in the opposite direction.

In summary, the present study suggests that (a) blind subjects do not outperform sighted subjects on tests of basic chemoreception, and (b) training on chemosensory tasks greatly facilitates performance on a number of such tests. Despite these findings, however, it is still possible that some forms of blindness may be associated with olfactory dysfunction. For example, individuals with retinitis pigmentosa have pathology in ciliated structures (i.e., the outer segments of the photoreceptors) that could conceivably extend, as in the case of Usher's syndrome (in which the kinocilia of the cochlea are affected), to other sensory systems. However, we recently administered UPSITs to 71 blind subjects with retinitis pigmentosa and found that their test scores did not differ from those of matched controls (Doty, unpublished data). Whether patients with Usher's syndrome have olfactory loss is currently under investigation.

\section{REFERENCES}

Amsterdam, J., Settle, R. G., Doty, R. L., Abelman, E., \& WINOKUR, A. (1987). Taste and smell perception in depression. Biological Psychiatry, 24, 831-839.

BAKER, R. A. (1962). Subjective panel testing. Industrial Quality Control, 19, 1-9.

Bartels, J. H. M, Burlingame, G. A., Suffet, I. H. (1986). The flavor profile analysis method: Taste and odor control of the future. Journal of the American Water Works Association, 78, 50-56.

Bertoloni, G. M. (1942). La capacita olfattoria nei ciechi. Marginalia Otolaryngologica, 43, 135-138.

Bilancioni, G. (1927). Disosmie, disgeuste e disturbi affini dal punto di vista clinico. Atti 23 Congresso della Societa Italiana di Laringologia Otologia e Rinologie, Venezia.

BoccuzzI, V. (1962). Ricerche sulla soglia olfattiva nei ciechi. Bollettino della Malattie dell'orecchio, della Gola e del Naso, 80, 445-467.

CaIN, W. S., \& Johnson, F., JR. (1978). Lability of odor pleasantness: Influence of mere exposure. Perception, 7, 459-465.

Cairncross, S. E., \& Suostrom, L. B. (1950). Flavor profiles: A new approach to flavor problems. Food Technology, 4, 308-311.

CaUL, J. F. (1957). The profile method of flavor analysis. Advances in Food Research, 7, 1-22.

Cherubino, M., \& Salis, B. (1957). Valutazione dell'acuita olfattiva nel cieco e nel sordomuto: Ulteriore contributo al sinergismo funzionale intersensorial. Bollettino della Malattie dellorecchio, della Gola e del Naso, 75, 239-251.

DeEms, D. A., \& Doty, R. L. (1987). The nature of age-related olfactory detection threshold changes in man. Transactions of the Pennsylvania Academy of Ophthalmology \& Otolaryngology, 39, 646-650.

Doty, R. L. (1978). Gender and reproductive state correlates of taste perception in humans. In T. E. McGill, D. A. Dewsbury, \& B. D. Sachs (Eds.), Sex and behavior: Status and prospectus (pp. 337-362). New York: Plenum.

Doty, R. L. (1986). Gender and endocrine-related influences on human olfactory perception. In H. L. Meiselman \& R. S. Rivlin (Eds.), Clinical measurement of taste and smell (pp. 377-413). New York: Macmillan.

Doty, R. L., Brugger, W. E., Jurs, P. C., Orndorff, M. A., SNYDER, P. J., \& LoWRY, L. D. (1978). Intranasal trigeminal stimulation from odorous volatiles: Psychometric responses from anosmic and normal humans. Physiology \& Behavior, 20, 175-187.

Doty, R. L., Frye, R. E., \& AgraWAL, U. (1989). Internal consistency reliability of the fractionated and whole University of Pennsylvania Smell Identification Test. Perception \& Psychophysics, 45, 381-384.

Doty, R. L., GREgor, T., \& SETTLE, R. G. (1986). Influences of intertrial interval and sniff bottle volume on the phenyl ethyl alcohol olfactory detection threshold. Chemical Senses, 11, 259-264.

Doty, R. L., Shaman, P., \& DanN, M. (1984). Development of the University of Pennsylvania Smell Identification Test: A microencapsulated test of olfactory function. Physiology \& Behavior, 226, 1441-1443.

Doty, R. L., Smith, R., McKeown, D., \& RaJ, J. (1993). Psychophysical tests of human olfactory function: Factor analytic evidence that most measure a common sensory domain. Manuscript submitted for publication.

Doty, R. L., SNyder, P., Huggins, G., \& Lowry, L. D. (1981). Endocrine, cardio-vascular, and psychological correlates of olfactory sensitivity changes during the human menstrual cycle. Journal of Comparative \& Physiological Psychology, 95, 45-60.

Eichendaum, H., Morton, T. H., Potter, H., \& Corkin, S. (1983). Selective olfactory deficits in case H. M. Brain, 106, 459-472.

ElsBerg, C. A., \& LeVY, I. (1935). The sense of smell: I. A new and 
simple method of quantitative olfactometry. Bulletin of the Neurological Institute of New York, 4, 5-19.

ENGEN, T. (1960). Effect of practice and instruction on olfactory thresholds. Perceptual \& Motor Skills, 10, 195-198.

GALTON, F. (1883). Inquiries into human faculty and its development. London: Macmillan.

Gault, R. H. (1923). An unusual case of olfactory and tactile sensitivity. Journal of Abnormal Psychology, 17, 395-401.

GRIESBACH, H. (1889). Vergleichende Untersuchungen über die sinnesschaerfe Blinder und Sehender. Archiv für die Gesamte Physiologie, 74, 577-638; 75, 365-429, 523-573.

Hicks, C. B. (1965). Your mysterious nose. Today's Health, 53, 35-37. JAMES, W. (1890). Principles of psychology. New York: Holt.

JEROME, E. A. (1942). Olfactory thresholds measured in terms of stimulus pressure and volume. Archives of Psychology, 274, 1-44.

JONES, F. N. (1953). A test of the validity of the Elsberg method of olfactometry. American Journal of Psychology, 66, 81-85.

MAHNER, P. (1909). Vergleichende psycho-physiologische Versuche über die Unterschiedungsfähigkeit im Gebiete des inneren und außeren Tastsinnes, des Geschmackes-, des Geruchssinnes an taubstummen, blinden, normalsinnigen, schwachsinnigen und taubstumm-blinden Kinderm. Inaugural-Dissertation zur Erlangung der Doktorwurde einer hohen philosophischen Fakultät der Universität Bern. Leipzig: Otto Wigand.

Mallevialle, J., \& SufFet, I. H. (1987). Identification and treatment of tastes and odors in drinking water (pp. 123-143). Denver: American Water Works Association.

McAuliffe, W. K., \& Meiselman, H. L. (1974). The roles of practice and correction in the categorization of sour and bitter taste qualities. Perception \& Psychophysics, 16, 242-244.

Moskowitz, H. R., Kumraiah, V., Sharma, K. N., Jacobs, H. L., \& Sharma, S. D. (1975). Cross-cultural differences in simple taste preferences. Science, 190, 1217-1218.

Murphy, C., \& CAIN, W. S. (1985). Odor identification: The blind are better. Physiology \& Behavior, 37, 177-180.

Pliner, P. (1982). The effects of mere exposure on liking for edible substances. Appetite: Journal for Intake Research, 3, 283-290.

Porter, R. H., \& Moore, J. D. (1981). Human kin recognition by olfactory cues. Physiology \& Behavior, 27, 493-495.
RABIN, M. D. \& CAIN, W. S. (1986). Determinants of measured olfactory sensitivity. Perception \& Psychophysics, 39, 281-286.

Rogers, P. J., \& HiLl, A. J. (1989). Breakdown of dietary restraint following mere exposure to food stimuli: Interrelationships between restraint, hunger, salivation, and food intake. Addictive Behaviors, 14, 387-397.

Stewart, D. (1815). Some accounts of a boy born blind and deaf, collected from authentic sources of information with a few remarks and comments. Transactions of the Royal Society of Edinburgh, 7, 1-78.

WALLACE, P. (1977). Individual discrimination of humans by odor. Physiology \& Behavior, 19, 577-579.

WENZEL, B. (1948). Techniques in olfactometry. Psychological Bulletin, 45, 231-246.

WILKINSON, L. (1990). SYSTAT: The system for statistics. Evanston, IL: SYSTAT, Inc.

Wysocki, C. J., Dorries, K. M., \& Beauchamp, G. K. (1989). Ability to perceive androstenone can be acquired by ostensibly anosmic people. Proceedings of the National Academy of Sciences USA, 86, 7976-7978.

\section{NOTES}

1. Although slightly different numbers of subjects took each of the tests, the sex ratios, years of education, relative proportion of smokers, and other subject attributes were similar from group to group. Therefore, we only provide demographic information for the parent groups in this section.

2. This group consisted of 1 trained panel member (UPSIT score $=$ 30 ) and 6 blind persons (UPSIT scores $=28,29,30,30,32,33$ ). These exclusions were made to ensure comparability across study groups, since the trained panel members were initially screened to have UPSIT scores $>33$. Analysis of the data with these individuals included did not change the results of the study.

(Manuscript received November 16, 1990; revision accepted for publication April 14, 1993.) 